\title{
Facilitation of implant provision in primary care
}

\author{
J. C. Field, ${ }_{1}^{1}$ N. Rousseau, ${ }^{2}$ J. M. Thomason, ${ }^{3}$ C. Exley, ${ }^{4}$ T. Finch, ${ }^{5}$ \\ J. G. Steele ${ }^{6}$ and J. S. Ellis
}
IN BRIEF
- Allows readers to appreciate the level of facilitation of implant provision within primary care.
- Highlights the need for informed consent when treatment planning for the edentulous patient.
- Promotes the implant-supported overdenture as an effective treatment option for the edentulous patient.
- Emphasises the need for further qualitative research into the decision-making process.

Objective To investigate primary care practitioner participation in implant-supported mandibular overdenture (ISOD) provision. Design Postal questionnaire. Setting Primary dental care, North East England 2007. Subjects and methods Two hundred and ninety-five practitioners in North East England were sent questionnaires presenting a case-based scenario of a patient unable to manage a lower denture on an atrophic ridge. The questionnaire led them through the facilitation stages of ISOD provision, asking them to state their anticipated level of participation at each stage. Demographic details were also collected. Results Two hundred and seventeen responses were received (74\%). Most practitioners would consider the option of provision of ISODs (89\%) in this case and all who considered would discuss the option with the patient. Of those offering to facilitate treatment, $66 \%$ (122/184) would never deliver themselves, with the majority (60\%, 111/184) referring within primary care. Statistical analysis showed associations between demographics and behaviour. Conclusions The majority of practitioners in this study area would facilitate ISOD provision in this case. Practitioners who are male and working in a practice where a framework for the provision of implants already exists are most likely to facilitate provision and/or provide an ISOD within primary care.

\section{INTRODUCTION}

The use of dental implants to support mandibular overdentures (ISODs) has a strong evidence base. The McGill consensus statement ${ }^{1}$ concluded that '...there is now overwhelming evidence that a twoimplant overdenture should become the first choice treatment for the edentulous mandible.' A recent systematic review of 18 randomised clinical trials ${ }^{2}$ shows a strong body of evidence supporting the premise that they improve both patient satisfaction and oral health-related quality of life. $^{3-5}$ Moreover, ISODs are an effective means of improving dietary freedom and, potentially, nutritional intake compared to

\footnotetext{
${ }^{1 *}$ Clinical Fellow in Restorative Dentistry, ${ }^{3}$ Professor of Prosthodontics and Oral Rehabilitation, ${ }^{7}$ Clinical Senior Lecturer, School of Dental Sciences, Newcastle University, Framlington Place, Newcastle, NE2 4AZ; ${ }^{2}$ Research Associate, ${ }^{4}$ Senior Lecturer in Medical Sociology, ${ }^{5}$ Senior Lecturer, ${ }^{6} \mathrm{Head}$ of School and Professor of Oral Health Services Research, Institute of Health and Society, Newcastle University, Newcastle NE1 7RU ${ }^{*}$ Correspondence to: James Field Email: james.field@ncl.ac.uk
}

\section{Online article number E20}

Refereed Paper - accepted 22 June 2009

DOI: 10.1038/sj.bdj.2009.1013

${ }^{\circledR}$ British Dental Journal 2009; 207: E20 conventional dentures. ${ }^{6}$ While the provision of such treatment has, in the past, largely been limited to specialist centres and secondary care environments, minimal training can enable inexperienced dental practitioners to provide successful mandibular two-implant overdentures for their patients. ${ }^{7}$

Broad interpretation of primary care dental services contracts and treatment banding in the UK theoretically allows the provision of ISODs within the National Health Service (NHS) provision framework. However, the current level of remuneration (Band 3) discourages this treatment strategy and within the NHS, ISOD provision is almost exclusively limited to secondary care environments. Despite the existence of guidelines identifying priority groups for implant provision, ${ }^{8}$ there is still marked variation in provision even within secondary care across the United Kingdom. ${ }^{9}$ While the option for private provision does exist, its availability is also likely to vary throughout the country.

Referral for secondary care treatment is largely achievable only through primary care practitioners who in essence act as 'gatekeepers' to this option. While referral within primary care (ie from one primary care practitioner to another) is also possible, patients themselves may independently identify and consult individual primary care practitioners who provide implant treatments.

There is evidence from outside the United Kingdom that practitioner variables such as their age and sex may influence the context of provision and treatment decisions regarding routine dental care. ${ }^{10-12}$ However, within the United Kingdom, little is known about the influence of practitioner characteristics on their facilitation of, and referral for, more specialist treatments such as ISODs.

The aim of this paper is to provide an insight into the level of facilitation of ISOD provision by primary care practitioners working in the North East of England. Part of a larger Medical Research Council funded project, ${ }^{13}$ it provides an initial analysis of the relationship between individual characteristics and demographics of primary care practitioners and their approach to managing implant care. 


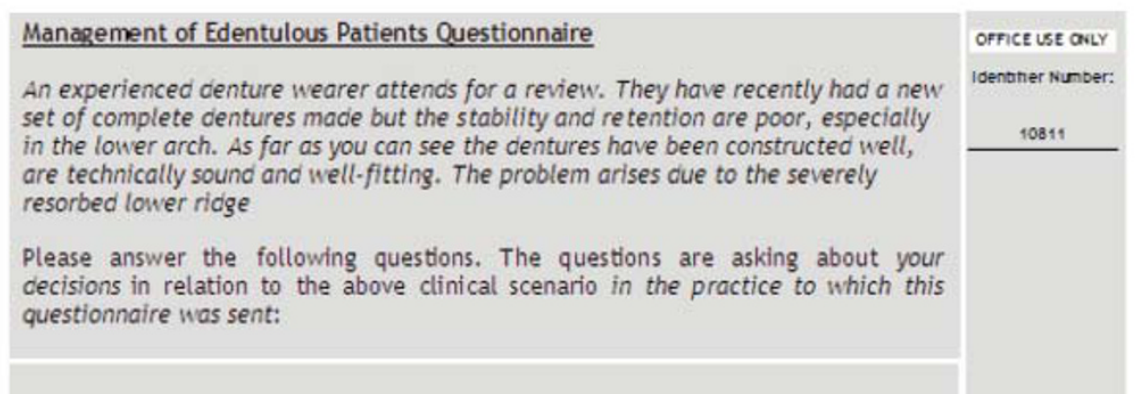

Fig. 1 Case-based scenario of severely resorbed lower ridge

\section{METHOD}

The study received favourable ethical opinion from the local Research Ethics Committee; the research sponsor was Newcastle upon Tyne Hospitals NHS Foundation Trust.

Individual practitioners were sent a letter inviting them to participate in the study. A confidential questionnaire and a pre-paid, addressed envelope for return of the questionnaires were posted to all primary care dental practitioners registered in the Newcastle, North Tyneside and Northumberland Primary Care Trusts lists. Details relating to the practitioners' sex and year of qualification (BDS) were obtained online through the General Dental Council register.

The questionnaire was designed to collect demographic information relating to the dental practitioners that were approached to take part in the study. Within this questionnaire, the practitioners were then presented with a case-based scenario (Fig. 1). The scenario described an individual struggling to tolerate a well-made lower denture on a severely resorbed ridge. Based on this scenario, the practitioners stated their anticipated level of participation at each stage of facilitation of ISOD provision (giving consideration to implants, discussing implants as an option, offering to facilitate provision, delivering any treatment or referring for treatment).

The response rate for the questionnaires was maximised using the strategies detailed in Table 1. One month after the initial posting, a postal reminder was sent to non-respondents along with another copy of the questionnaire and a further pre-paid envelope.

Statistical analysis was performed using SPSS (version 15.0 for Windows). Univariate descriptive analyses were used to initially examine the frequency distribution of study variables. Continuous independent variables were transformed into categorical variables to enable Pearson chi-square and multiple logistic regression analyses; categorical dependent variables ('always', 'sometimes', 'rarely', 'never') were recoded as dichotomous variables following discussion between all authors about where the meaningful boundaries between levels of facilitation lay (eg 'always/sometimes', or 'rarely/never'). In all statistical analyses, a probability level of $\mathrm{p}<0.05$ served as the criterion for statistical significance. Missing values were excluded from the analysis on a pairwise basis (ie only missing data were removed, cf a listwise exclusion, where the entire data set for that respondent is removed). We did not impute values for missing data.

There was a strong relationship between age and sex of practitioners, with more female practitioners in the younger age groups (Table 2). In light of this, a logistic regression analysis was used to adjust for potential interaction between these factors. We hypothesised (on the basis of the linked qualitative study) ${ }^{13}$ that the presence of an implant provider within the practice might alter the behaviour of other practitioners within the same practice. For each stage of implant facilitation, two models were therefore tested: one for the entire sample of practitioners using age and sex, and a second model for non-providers of implants in group practices only $(\mathrm{n}=138$; those responding 'rarely or never' to the question 'would you provide any part of
Table 1 Strategies for increasing

responses to postal questionnaires (modified ${ }^{21,22}$ )

\begin{tabular}{l}
\hline Method \\
\hline Newcastle University Crest on the envelope \\
\hline Pre-notification \\
\hline Follow up contact \\
\hline
\end{tabular}

Questionnaire kept relatively short

Providing a second copy of the questionnaire at follow-up

Personalised letters

Anonymous questionnaires

Use of coloured ink and high quality paper

Used of stamped return envelopes instead of franked

Assurance of confidentiality

First class mailing outward

No staples

the implant treatment yourself?') where the impact of having another practitioner providing implants in the practice was tested in addition to age and sex. Forward stepwise regression models were used, with an entry criterion of 0.05 and a stay criterion of 0.1. Odds ratios are presented only for those variables entering the forward stepwise regression model; the models were recalculated with all covariates (age, sex and, for model 2, presence of an implant provider) forced into the regression. The odds ratios shown are those adjusted for the effects of these confounding variables.

\section{RESULTS}

Three hundred and sixty-two primary care practitioners were identified from PCT lists. Of these, 67 practitioners were found either to have left the practice or retired, were currently on maternity leave or were absent because of long-term illness, so reducing the actual sample size to 295. Two hundred and seventeen questionnaires were returned (74\%). Eight practitioners reported working in more than

Table 2 Age and sex of respondents
\begin{tabular}{|l|l|l|l|l|l|}
\hline & $<30$ years & $\mathbf{3 0 - 3 9}$ years & $\mathbf{4 0 - 4 9}$ years & $\mathbf{5 0}$ years + & Total respondents \\
\hline Male (\%) & $22(16)$ & $29(22)$ & $45(34)$ & $37(28)$ & 133 \\
\hline Female (\%) & $25(35)$ & $22(31)$ & $18(25)$ & $6(9)$ & 71 \\
\hline
\end{tabular}
Pearson chi-sq 17.881; df $3 ; p<0.001$


Table 3 Percentages of practitioners participating at each treatment negotiation stage

\begin{tabular}{|c|c|c|c|c|c|}
\hline $\begin{array}{l}\text { ISOD treatment } \\
\text { stage }\end{array}$ & $\begin{array}{l}\text { Number of } \\
\text { responses }\end{array}$ & Always (\%) & Sometimes (\%) & Rarely (\%) & Never (\%) \\
\hline Consider & 209 & 23.4 & 44.0 & 21.5 & 11.0 \\
\hline Discuss & 186 & 50.5 & 35.5 & 14.0 & 0.0 \\
\hline Deliver & 184 & 9.8 & 13.6 & 10.3 & 66.3 \\
\hline Refer $1^{\circ}$ & 184 & $60.3^{1}$ & 23.4 & 7.6 & 8.7 \\
\hline Refer $2^{\circ}$ & 73 & 16.4 & 52.1 & 20.5 & $11.0^{1}$ \\
\hline
\end{tabular}

one practice and returned two questionnaires. Where this was the case, only one of the questionnaires for this practitioner was included in the analysis. This choice of questionnaire was selected using a random numbers table. Two hundred and nine responses were therefore used for final data analysis. Respondents did not differ from non-respondents in terms of year of qualification (mean years since BDS: 17 years for responders, 17.5 years for non-responders; independent samples t-test (2-tailed) $\mathrm{p}=0.729$ ) or sex (response rate for women: 72/93, 77.4\%; response rate for men: 137/177, 77.4\%; Pearson chi-square 0.000 df $1 \mathrm{p}=0.997$ ).

The number of practitioners that would anticipate their involvement at each of the stages of facilitation of treatment (consider, discuss, deliver or refer) is shown in Table 3.

\section{Treatment stage: Consideration of ISODs as a treatment option}

In relation to the initial aspects of implant provision (consideration and discussion) only 23\% (49/209) of practitioners reported that they would always consider ISODs, while 11\% (23/209) reported that they would never consider ISODs as a potential treatment option in this case-based scenario. Practitioners over the age of 50 were less likely to consider ISODs than their younger colleagues (Table 4), and this association remained statistically significant after adjusting for sex in the logistic regression model (odds ratio (OR) 0.29; 95\% confidence interval (CI) 0.11-0.73). Men and women were equally likely to say that they would consider implant treatment. Practitioners who were not implant providers and were in group practices were more likely to consider treatment sometimes or always if there was an implant provider in the practice (Table 5; $84 \%$ compared with $51 \%$ in practices without an implant provider, $\mathrm{p}<0.001$ ), and this association remained statistically significant after adjusting for age and sex (OR 4.37; 95\% CI 1.76-10.84).

\section{Treatment stage: Discussion of ISODs as a treatment option}

All 186 ( $\mathrm{n}=209$ - 23) practitioners that would initially consider ISODs would then proceed to discuss them with the patient (Table 3). Male practitioners (90\%) were more likely than female practitioners (79\%) to say that they would always or sometimes discuss ISOD provision with their patients ( $\mathrm{p}=0.035$; OR after adjusting for age 2.49; CI 1.03-6.00). 'Nonproviders' in group practices were more likely to discuss treatment always or sometimes if there was an implant provider in the practice (94\% (46/49) compared with 72\% (54/75) in practices without an implant provider; $p=0.003$ ), and this association remained statistically significant after adjusting for age and sex (OR 6.83; 95\% CI 1.85-25.21). Only two practitioners discussing ISODs with the patient said that they would then never offer to facilitate treatment.

\section{Treatment stage: Practitioners delivering any aspect of ISOD treatment themselves}

Of the 184 practitioners who would (always, sometimes or rarely) offer to facilitate ISOD provision, 10\% ( $\mathrm{n}=18$ ) said that they would always provide some aspect (implant placement or restoration) themselves but 122 (66\%) said that they would never deliver any treatment (Table 3). Men were more likely than women to say that they would carry out some part of the ISOD treatment, with 30\% saying that they would at least sometimes deliver compared to only $11 \%$ of females ( $p=0.003$; OR after adjusting for age 3.83; CI 1.48-9.91). There was no effect of age on whether a practitioner would deliver any treatment themselves.

\begin{tabular}{|c|c|c|c|c|c|c|c|c|}
\hline ISOD treatment stage & Male & Female & $\begin{array}{l}\text { Pearson } \\
\text { chi-square }\end{array}$ & $<30$ & $30-39$ & $40-49$ & $50+$ & $\begin{array}{l}\text { Pearson } \\
\text { chi-square }\end{array}$ \\
\hline Always or sometimes consider & $\begin{array}{l}93 / 137 \\
67.9 \%\end{array}$ & $\begin{array}{l}48 / 72 \\
66.7 \%\end{array}$ & $\begin{array}{l}0.032 \\
d f 1 \\
p=0.858\end{array}$ & $\begin{array}{l}34 / 47 \\
72.3 \%\end{array}$ & $\begin{array}{l}37 / 51 \\
72.5 \%\end{array}$ & $\begin{array}{l}46 / 63 \\
73.0 \%\end{array}$ & $\begin{array}{l}20 / 43 \\
46.5 \%\end{array}$ & $\begin{array}{l}10.54 \\
\text { df } 3 \\
p=0.015\end{array}$ \\
\hline Always or sometimes discuss & $\begin{array}{l}108 / 120 \\
90.0 \%\end{array}$ & $\begin{array}{l}52 / 66 \\
78.8 \%\end{array}$ & $\begin{array}{l}4.45 \\
\text { df } 1 \\
p=0.035\end{array}$ & $\begin{array}{l}39 / 46 \\
84.8 \%\end{array}$ & $\begin{array}{l}41 / 47 \\
87.2 \%\end{array}$ & $\begin{array}{l}48 / 58 \\
82.8 \%\end{array}$ & $\begin{array}{l}27 / 30 \\
90.0 \%\end{array}$ & $\begin{array}{l}0.98 \\
\text { df } 3 \\
p=0.806\end{array}$ \\
\hline Always or sometimes deliver & $\begin{array}{l}36 / 119 \\
30.3 \%\end{array}$ & $\begin{array}{l}7 / 65 \\
10.8 \%\end{array}$ & $\begin{array}{l}8.91 \\
d f 1 \\
p=0.003\end{array}$ & $\begin{array}{l}7 / 46 \\
15.2 \%\end{array}$ & $\begin{array}{l}8 / 46 \\
17.4 \%\end{array}$ & $\begin{array}{l}18 / 57 \\
31.6 \%\end{array}$ & $\begin{array}{l}8 / 30 \\
26.7 \%\end{array}$ & $\begin{array}{l}5.00 \\
\text { df } 3 \\
p=0.172\end{array}$ \\
\hline $\begin{array}{l}\text { Always or sometimes refer } \\
\text { to primary care }\end{array}$ & $\begin{array}{l}99 / 119 \\
83.2 \%\end{array}$ & $\begin{array}{l}55 / 65 \\
84.6 \%\end{array}$ & $\begin{array}{l}0.06 \\
d f 1 \\
p=0.803\end{array}$ & $\begin{array}{l}40 / 46 \\
87.0 \%\end{array}$ & $\begin{array}{l}41 / 46 \\
89.1 \%\end{array}$ & $\begin{array}{l}45 / 57 \\
78.9 \%\end{array}$ & $\begin{array}{l}24 / 30 \\
80.0 \%\end{array}$ & $\begin{array}{l}2.61 \\
d f 3 \\
p=0.456\end{array}$ \\
\hline $\begin{array}{l}\text { Always or sometimes refer } \\
\text { to secondary care }\end{array}$ & $\begin{array}{l}25 / 119 \\
21.0 \%\end{array}$ & $\begin{array}{l}25 / 65 \\
38.5 \%\end{array}$ & $\begin{array}{l}6.47 \\
d f 1 \\
p=0.011\end{array}$ & $\begin{array}{l}15 / 46 \\
32.6 \%\end{array}$ & $\begin{array}{l}14 / 46 \\
30.4 \%\end{array}$ & $\begin{array}{l}16 / 57 \\
28.1 \%\end{array}$ & $\begin{array}{l}5 / 30 \\
16.7 \%\end{array}$ & $\begin{array}{l}2.54 \\
\text { df } 3 \\
p=0.469\end{array}$ \\
\hline
\end{tabular}


Treatment stage:

\section{Referral for ISOD treatment}

Of those who would facilitate but not deliver any aspect of treatment themselves ( $n=166$ ), the majority said that they would always refer to primary care $(\mathrm{n}=111,60 \%)$ while $9 \%(n=16)$ would never refer to a colleague in primary care. Of those that did not always refer to primary care $(n=73)$, the vast majority $(89 \%, n=65)$ said that they would refer to secondary care. There were no significant differences by sex of practitioner in terms of whether or not practitioners would refer to primary care. However, male practitioners were less likely to say that they would refer to secondary care than female practitioners (Table 4) and this relationship remained statistically significant after adjusting for age (OR 0.47; CI 0.23-0.93). Age of the practitioner and for non-providers, the presence of an implant provider in the practice, made no difference to reported referral to either primary or secondary care.

\section{DISCUSSION}

There has been little published information about the proportion of dental practitioners who are involved in implant provision within primary care. In this study, over $20 \%$ of practitioners in the North East of England said that they would always or sometimes provide some of the treatment in the case of an implant supported mandibular overdenture; provision varied with the sex of the practitioner. We also found that $11 \%$ of practitioners would never consider an ISOD as a treatment option in this scenario.

A strength of this study is the high response rate (achieved with the methods shown in Table 1). This, together with the lack of difference between responders and non-responders, would suggest that the findings of this study are representative of the target population. However, the practitioners were asked to respond to a hypothetical case-based scenario which deliberately lacked detail regarding the patient's medical and dental history, demographics, social status and personal motivation towards implants. The McGill consensus statement was solely concerned with implant provision for the edentulous individual, and the case scenario presented was intended to describe a dental patient who was encompassed by this statement.

Table 5 Individual provision within provider and non-provider practices. Would you consider implant treatment? Non-providers (those who said they would provide some ISOD treatment themselves rarely or never) in group practices ${ }^{1}$ by whether there is a provider within the practice

\begin{tabular}{|c|c|c|c|c|c|c|}
\hline $\begin{array}{l}\text { ISOD Treatment } \\
\text { stage }\end{array}$ & $\begin{array}{l}\text { Number of } \\
\text { responses }\end{array}$ & $\begin{array}{l}\text { Always } \\
(\%)\end{array}$ & $\begin{array}{l}\text { Sometimes } \\
(\%)\end{array}$ & $\begin{array}{l}\text { Rarely } \\
(\%)\end{array}$ & $\begin{array}{l}\text { Never } \\
(\%)\end{array}$ & $\begin{array}{l}\text { Total } \\
(\%)\end{array}$ \\
\hline $\begin{array}{l}\text { In a practice } \\
\text { with a provider }\end{array}$ & 51 & 31.4 & 52.9 & 11.8 & 3.9 & 100 \\
\hline $\begin{array}{l}\text { Not in a practice } \\
\text { with a provider }\end{array}$ & 87 & 13.8 & 36.8 & 35.6 & 13.8 & 100 \\
\hline
\end{tabular}

The findings must therefore be seen in the context of this scenario. The practitioners' reported levels of facilitation might have been different in light of a more comprehensive case history, in relation to alternative patterns of tooth loss or if a definite level of service provision had been suggested. Nonetheless, by using a relatively broadly specified case, it is possible to see the wider picture of attitudes towards this approach to treatment.

It could be assumed that if a practitioner never considers a particular treatment, they are either unaware of its existence or have elected not to adopt the treatment into their practising philosophy. The latter will inevitably be the result of a personal synthesis of information available to that individual, and may include wider issues outside of the scientific evidence base. Eleven percent of the practitioners in this study population would never consider ISODs for this case-based scenario. The McGill consensus statement was published seven years ago and is supported by a stronger evidence base than is found elsewhere in dentistry. Osseointegrated implants have been used to support overdentures in the UK for over 20 years. It is likely that, even if they were unaware of the consensus statement, all practitioners would be aware of the use of dental implants in this scenario. The assumption is therefore that those not considering their use are either unaware of the extent of the evidence base (or have determined that the evidence base is flawed) or have decided the implications of adopting a new treatment philosophy and potentially changing their working practice are of no benefit to themselves or their patients. Indeed, in this study, there was a tendency for those less likely to consider ISODs to be older or those working in a non-implantproviding practice, which would support these assumptions. The uptake of implant technology into practice may currently be considered a vocational skill, in the sense that the required knowledge, skills and attitudes are acquired and reinforced in the workplace, rather than in an academic environment. This is likely to change as implant treatment becomes more commonplace and its theory and practice become embedded in undergraduate curricula.

Practising dentists were identified using primary care trust lists and were therefore involved, to some degree, in the provision of care under NHS regulations. Within the study area (North East of England) there are lower reported levels of private dental care than some other areas of the UK. ${ }^{14}$ No attempt was made to determine the proportions of NHS and/or private treatment, and how this related to the observed responses. Similarly, no mention was made of level of service provision (private $v s$ NHS) within the scenario. However, it is probable that the context in which dentistry is undertaken will influence practitioners' behaviours and patterns of treatment. This is borne out by the findings that practitioners are more likely to consider implants if they were working within a practice with an implant provider (often presumably linked to private provision). However, regardless of the context of service provision, or patient circumstance, it is a central tenet of professionalism to consider and discuss treatment that may be in the patient's best interests. In this particular scenario, no other conventional treatment modality exists that can reliably improve the patient's oral health-related quality of life. There is a strong evidence base to support the consideration of implant-supported overdentures, which consistently demonstrates increased patient satisfaction and improved quality of life. ${ }^{2}$ At the very least, all practitioners should consider and 
the majority should discuss implants as a treatment option, regardless of their personal working context or any assumptions they make with regard to the patient's ability to finance their treatment. ${ }^{15}$ Although $11 \%$ would not even consider implants and the nature and extent of any subsequent discussions are unknown, it is encouraging that in this study all of the practitioners considering ISODs said they would subsequently discuss them with the patients.

Despite the vast majority of practitioners facilitating ISOD provision, most practitioners would never deliver any of the treatment themselves and only 10\% would always deliver at least some of the treatment themselves. This questionnaire did not elucidate which aspects of implant provision practitioners anticipated delivering. It is possible that poor access to implant placement opportunities and training opportunities may also deter practitioners from undertaking the nonsurgical restorative procedures. Previous studies of other healthcare professionals (Australasian emergency physicians) have demonstrated an increased confidence in surgical skills in male practitioners. ${ }^{16}$ In this case-based scenario, males were more likely to deliver any aspects of treatment and this may be linked to an increased confidence in their surgical skills base and so openness to some surgical involvement. Males are more likely to be practice owners ${ }^{17}$ so investment in practice equipment and facilities is therefore more likely to be in their control. Market research data suggests that the consumers who are currently adopting new technologies are also more likely to be male ${ }^{18}$ and this may partly explain an increased engagement of the men in this study with new technologies and equipment.

In this sample, for the scenario given, practitioners reported that they would be more inclined to refer (privately) within primary care rather than into secondary care (for NHS-funded treatment). A previous study in a similar geographical area ${ }^{19}$ also reported low levels of secondary care referral for implant treatment and suggested that this might be due to an awareness of strict protocols for patient acceptance within the secondary care environment and a lack of clarity regarding referral to secondary care in general.
Female practitioners were more likely to refer to a colleague in secondary care than were male practitioners. Female practitioners are more likely than male practitioners to be working part-time, at multiple practices, within salaried dental services, and treating NHS patients. ${ }^{14,17,20}$ Implant treatment has only limited availability within secondary care and thus practitioners may be inclined only to refer those patients who they perceive cannot pay for implant treatment privately. The association between female practitioners and secondary care referral may thus be partially explained by differing patient populations.

Although there are sex and age effects, it seems that, not surprisingly, the presence of another practitioner in the same practice who already provides implants has the largest effect on practitioner behaviour (though it is important to note that this does not appear to affect propensity to refer to secondary care). This suggests that there is an uneven distribution of practitioners who would participate at each stage of ISOD provision, potentially resulting in a proportion of patients who are excluded from this treatment strategy. The evidence base for ISODs is very strong and perhaps, therefore, patients struggling to manage a well-made lower complete denture should always be given this treatment option, irrespective of who will or will not pay for it. It must be stressed that offering to facilitate the provision of ISODs is very different from offering to provide. There is a responsibility on behalf of all dental practitioners to provide patients with information regarding relevant treatment options in order to ensure that they are able to give informed consent. It may very well be that when treatments such as ISODs are not offered to patients where they have a recognised value, practitioners are making subtle judgements (albeit perhaps very valid) on behalf of their patients. In making these judgements, practitioners may inappropriately limit the availability of such treatment by underestimating the value that patients would place on them. The responsibility for ensuring that all patients have equal access to treatment also lies with the General Dental Council (who may need to periodically remind dental care professionals of the need for informed consent, detailing all available treatment options), the educational bodies to train students appropriately in contemporary treatment strategies and perhaps even industry, to help make novel treatment options more widely accessible.

The original aim of the paper was to provide an insight into the level of facilitation of ISOD provision by primary care practitioners. The decision-making process is clearly too complicated to deal with in a questionnaire survey. However, this highlights the need for further qualitative work in order to further unpick the obvious complexities of the process.

\section{CONCLUSION}

In conclusion, the vast majority (89\%) of practitioners from the study area would facilitate the provision of ISODs in this case-based scenario. However, by contrast, $11 \%$ would never even consider them as a treatment option. There remains limited availability of implant treatment within primary care, with only $10 \%$ of practitioners who would consider ISODs routinely providing treatment themselves. Of the remainder, the majority would refer to a colleague in primary care. Several significant associations between demographics and practitioner behaviour were identified in bivariate analyses but in a logistical model, practitioners who were male and working in a practice where a framework for the provision of implants already exists were most likely to facilitate and provide an implant-supported mandibular overdenture within primary care.

1. Feine J S, Carlsson G E, Awad M A et al. The McGill consensus statement on overdentures. J Prosthet Dent 2002; 88: 123-124.

2. Thomason J M, Heydecke G, Feine J S, Ellis J S. How do patients perceive the benefit of reconstructive dentistry with regard to oral health related quality of life and patient satisfaction? Clin Oral Implants Res 2007; 18: 168-188.

3. Awad M, Lund J, Dufresne E, Feine J S. Comparing the efficacy of mandibular implant-retained overdentures and conventional dentures among middle-aged edentulous patients: satisfaction and functional assessment. Int J Prosthodont 2003; 16: 117-122.

4. Heydecke G, Penrod J R, Takanashi Y, Lund J P, Feine J S, Thomason J M. Cost-effectiveness of mandibular two-implant overdentures and conventional dentures in the edentulous elderly. J Dent Res 2005; 84: 794-799.

5. Raghoebar G M, Meijer H J, van't Hof M, Stegenga $B$, Vissink A. A randomised prospective clinical trial on the effectiveness of three treatment modalities for patients with lower denture problems. A 10 year follow up study on patient satisfaction. Int J Oral Maxillofac Surg 2003; 32: 498-503.

6. Ellis J S, Thomason J M, Jepson N J, Nohl F, Smith D G, Allen PF. A randomized-controlled trial of food choices made by edentulous adults. 
Clin Oral Implants Res 2008; 19: 356-361.

7. Esfandiari S, Lund J P, Thomason J M. General dentists can provide successful implant overdentures with minimal training. J Dent 2006; 34: 796-801.

8. Faculty of Dental Surgery of the Royal College of Surgeons of England. National clinical quidelines 1997. London: Royal College of Surgeons of England, 1997.

9. Butterworth C J, Baxter A M, Shaw M J, Bradnock G. The provision of dental implants in the National Health Service Hospital Dental Services - a national questionnaire. Br Dent J 2001; 190: 93-96.

10. el-Mowafy 0 M, Lewis D W. Restorative decision making by Ontario dentists. J Can Dent Assoc 1994; 60: 313-316.

11. Kronstrom M, Palmqvist $S$, Eriksson T, Soderfeldt B, Carlsson G E. Practice profile differences among Swedish dentists. A questionnaire study with special reference to prosthodontics. Acta Odontol Scand 1997; 55: 265-269.
12. Kronstrom M, Palmqvist $S$, Soderfeldt $B$, Carlsson $G$ E. Dentist-related factors influencing the amount of prosthodontic treatment provided. Community Dent Oral Epidemiol 2000; 28: 185-194.

13. Exley C, Rousseau N, Steele J et al. Paying for treatments? Influences on negotiating clinical need and decision-making for dental implant treatment. BMC Health Serv Res 2009; 9: 7.

14. Buck D, Newton J T. The privatisation of NHS dentistry? A national snapshot of general dental practitioners. Br Dent J 2001; 190: 115-118.

15. General Dental Council. Principles of patient consent. London: GDC, 2006.

16. Dent A W, Paltridge D, Weiland J. Australasian emergency physicians: a learning and educational needs analysis. Part six: differences in confidence, exposure to learning and expressed learning needs by subgroups of Australasian emergency physicians. Emerg Med Australas 2008; 20: 347-356.
17. Ayers K M S, Thomson W M, Rich A M, Newton J T. Gender differences in dentists' working practices and job satisfaction. J Dent 2008; 36: 343-350.

18. Ipsos MORI. 1997-2007: ten years of measuring technology use. London: Ipsos MORI, 2007.

19. Fairbrother KJ, Nohl F S A. Restorative dentistry: perceptions of general dental practitioners of a local secondary care service in restorative dentistry. BrDent J 2000; 188: 99-102.

20. Newton J T, Thorogood N, Gibbons D E. The work patterns of male and female dental practitioners in the United Kingdom. Int Dent J 2000; 50: 61-68.

21. Edwards P, Roberts I, Clarke M. How to increase response rates to postal questionnaires. Evid Based Dent 2007; 8: 5-6.

22. Puffer S, Porthouse J, Birks Y, Morton V, Torgerson $D$. Increasing response rates to postal questionnaires: a randomised trial of variations in design. J Health Serv Res 2004; 9: 213-217. 